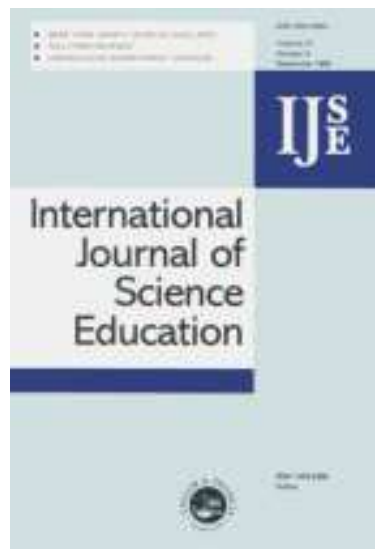

The Benefits of Residential Fieldwork for School Science: Insights from a Five-year Initiative for Inner-City Students in the UK

\begin{tabular}{|r|l|}
\hline Journal: & International Journal of Science Education \\
\hline Manuscript ID: & TSED-2010-0255.R2 \\
\hline Manuscript Type: & Research Paper \\
\hline Keywords: & fieldwork, informal learning, social domain \\
\hline Keywords (user): & \\
\hline
\end{tabular}

SCHOLARONE $^{\text {m }}$

Manuscripts 


\title{
The Benefits of Residential Fieldwork for School Science: Insights from a Five-year Initiative for Inner-City Students in the UK
}

\begin{abstract}
There is considerable international interest in the value of residential fieldwork for school students. In the UK, pressures on curriculum time, rising costs and heightened concern over students' safety are curtailing residential experiences. Collaboration between several key fieldwork providers across the UK created an extensive programme of residential courses for 11-14 year olds in London schools from 2004-2008. Some 33,000 students from 849 schools took part. This paper draws on the evaluation of the programme that gathered questionnaire, interview and observational data from 2706 participating students, 70 teachers and 869 parents / carers from 46 schools mainly in deprived areas of the city. Our findings revealed that students' collaborative skills improved and interpersonal relationships were strengthened and taken back to school. Gains were strongest in social and affective domains, together with behavioural improvements for some students. Individual cognitive gains were revealed more convincingly during face-to-face interviews, rather than through survey items. Students from socially deprived backgrounds benefitted from exposure to learning environments which promoted authentic practical inquiry. Over five year programme, combined physical adventure and real-world experiences proved to be popular with students and their teachers, and opened up opportunities for learning and doing science in ways not often accessible in urban school environments. Further programmes have been implemented in other parts of the UK as a result of the London experience, which build upon the provision of mixed curriculum-adventure course design. The popularity and apparent success of these combination courses suggest that providers need to consider the value of developing similar programmes in the future.
\end{abstract}




\section{Introduction}

There has long been a philosophy that learning outside the classroom is a positive educational experience for young people and to a certain extent this notion has been substantiated by research. Out of classroom learning is often cited as contributing positively to students' ideas about and enjoyment of science (Cerini, Murray and Reiss, 2003; Zoldosova and Prokop, 2006; Prokop, Tuncer and Kvasnicak, 2007). As curriculum authorities across the world try to increase numbers of students studying science beyond compulsory years (Millar and Osborne, 1998; Schreiner, 2006; USA National Academy of Science, 2007), inspiring strategies for motivating young people in science are important. Traditionally, many school curricula have placed importance on hands-on out-of-classroom activities such as fieldwork in subjects such as geography, environmental science, history and science itself (Brookes, 2002; Hart, 2002; DfeS, 2004; Braund and Reiss, 2006; Scharfenberg, Bogner and Klutke, 2008). Moreover, authenticity afforded by such opportunities has shaped some innovative approaches to science curricula in countries (for example, Canada and Australia) with a tradition of promoting the importance of cultural relevance and 'real-world' experience for meaningful learning (Roth, van Eijck, Reis and Hsu, 2008). Hodson (2008), amongst others, also suggests that school science practical inquiry lends purpose to 'doing science' and this assertion can readily be extended beyond the laboratory.

In the UK, science educators and outdoor education providers became increasingly alarmed by the beginning of the twenty first century at the demise of science fieldwork (Lock and Tilling, 2002; Tilling, 2004). Lock (2010) confirms evidence of this demise in a recent examination of nine studies conducted since 1963. In 2003, the Field Studies Council (FSC), a prominent charitable fieldwork provider in the UK, with a long-standing reputation for high 
quality fieldwork provision, began to undertake research into fieldwork provision in inner city schools, with a view to supporting such provision for students from deprived backgrounds. Improving success rates in toto for socio-economically deprived students continues to present education policy makers in the UK with the greatest of challenges (Feinstein, 2003; Chowdry, Crawford and Goodman, 2009).

Several factors seemed to contribute to the UK decline in fieldwork in school science (Lock, 2010). Senior managers were becoming reluctant to sanction science fieldwork visits (FSC internal report) in the midst of increasing pressures from the content-laden science National Curriculum for England and Wales (DfES, 1988, 1995). Teaching unions were advising caution about organising field visits in the light of health and safety concerns, and teacher confidence in taking students outside was variable (Ofsted, 2004). Moreover, there were concerns about the consistency of fieldwork training for secondary science pre-service teachers (Kendall, Murfield, Dillon and Wilkin, 2006). Parents / carers (hereafter 'parents' are taken to include 'carers') often had difficulties meeting the costs of fieldwork, particularly when residential. If a more positive environment for school students' participation in science fieldwork was to be established in the UK, all these factors needed to be addressed, making the situation a complex one. Teachers, senior managers and parents, as well as curriculum authorities and governments, needed to be convinced of the benefits of fieldwork in the wider context of students' education.

The purpose of this paper is to explore the expectations for, and perceived benefits of, residential fieldwork for 11-14 year old students from socially deprived areas in London, UK, participating in a distinctive FSC-led out-of-classroom programme from 2004 to 2008. 


\section{The Potential Benefits of Fieldwork in School Science}

Braund and Reiss (2006) argue for the potential of learning outside the classroom to improve school students' attitudes toward studying science, as well as to afford school science with greater authenticity. Roth et al. (2008), amongst others, continue to explore the appropriateness of authentic provision via informal experiences in science education from a young person's perspective, citing multiple benefits in creating opportunities for local, reallife projects. There is growing evidence that alongside students learning and doing science, there are opportunities for socialisation and building self confidence. Indeed, many studies have highlighted the personal, socio-cultural and physical benefits associated with informal learning (for example, Falk and Dierking, 2000). Rickinson, Dillon, Tearney, Morris, Choi, Sanders and Benefield (2004) suggest that much research into outcomes of outdoor learning is descriptive rather than empirical, and that whilst useful in itself, there needs to be a more rigorous approach to exploring the benefits that might actually occur in fieldwork contexts. This is a difficult goal. Several studies indicate that even the fundamental actions of capturing valid data in informal contexts can be challenging for researchers (Leeming, Dwyer, Porter and Cobern, 1993; Osborne and Dillon, 2007).

\section{Defining Learning Outside the Classroom}

Learning outside the classroom takes place in many settings; traditional biology or geology fieldwork often involves a few days of immersion in a rural environment with students taking part in observation, data collection and analysis. However, in the UK at present, only students of science continuing with biology after the age of 16 are likely to experience such learning 
Given the examination-oriented nature of much fieldwork, one could argue that the focus on 'what is being learnt' dominates other possible questions about the benefits of fieldwork and out-of-classroom experiences. Falk and Dierking (2000) challenged the 'what has been learnt?' scenario in a museum context. They asserted that such a question is fundamentally flawed and that a much more salient and useful enquiry would involve discovering how an out of classroom experience contributes to what a person 'knows, feels, believes or is capable of doing' (p13). As a result of their research Falk and Dierking developed a contextual model which puts forward the view that all learning takes place within three interlinked contexts: the personal, the socio-cultural and the physical. After 10 years of working with this model, they concluded that a fourth dimension - time - played an essential part in the learning process and to look at any learning experience as a 'snapshot' (p10) in time was not adequate for a full understanding of how learners make meaning.

Measuring degrees of tangible cognitive development, especially over the longer term, has challenged researchers. Moving on from a snapshot assessment of learning during fieldwork experiences to a longitudinal study is problematic because, often by the nature of student samples, measuring immediate learning is most feasible for researchers (Leeming et al., 1993). Beyond the field course itself, inputs from school science and from life experiences obviously continue to make contributions to student learning. Many school science teachers may lack appreciation of the nature of learning that can take place in out-of-classroom settings. Their own experience is often embedded in classroom pedagogy, pursuing learning 
outcomes arising from a content-laden curriculum. The critical pre-fieldwork and postfieldwork input that is needed for students to make meaningful progress is frequently underestimated, or bypassed, by busy science teachers.

In order to understand the complexities of learning outside the classroom, it is helpful to turn to the distinction between formal and informal learning. Formal learning is notably structured, compulsory and usually teacher-led, whereas informal learning is spontaneous, voluntary and student-led (Wellington and Ireson, 2008). As previously noted, whilst examination assessment is more characteristic of formal learning, in the UK, there is prevalent use of fieldwork for the purposes of examination coursework in biology. In the context of practical inquiry, in which the London Challenge field course activities were situated, a third classification of 'learning' (that of non-formal learning) is perhaps more pertinent here (Eshach, 2007). Eshach describes learning in non-formal settings as being structured and tutor- or guide-led but more flexible than formal learning. There are often unintended outcomes associated with informal, and perhaps non-formal, learning and the social nature of activities plays a central role. This is not a new concept (Wood, 1998), and has been taken up in the UK in recent curriculum revision (DfES, 2005).

In 2004, a review of international research into the impacts and benefits of fieldwork was undertaken (Rickinson et al., 2004). Often, as a result of the confines of study design, researchers have taken a rather limited view of the definition of learning. Previously, the acquisition of facts and skills related directly to school curricula was likely the main research focus in traditional fieldwork (for example, Lai, 1999). Other studies examining outcomes during adventure-based outdoor learning have centred primarily on students' abilities to solve problems and to develop teamwork skills. Rickinson et al.'s 2004 meta-analysis, based upon 


\section{The London Challenge Fieldwork Programme}

In 2003, the London Challenge initiative (a government-funded inner city project) pledged to provide a fully-funded residential experience for 11-14 year old state secondary school students from socially deprived areas in London. The FSC, and associate providers, responded by approaching the then Department for Education and Skills, with a proposal to run funded residential adventure and fieldwork courses.

The Structure of the London Challenge Programme 
The London Challenge courses were of three types:

- curriculum (traditional fieldwork, in ecology or geology, for example);

- adventure;

- combined curriculum-adventure.

All courses offered a range of structured or semi-structured activities, thereby fitting most closely attributes of non-formal learning (Eshach, 2007). Curriculum activities began and ended with classroom sessions, whereas students were briefed outside during adventure activities. Three types of science curriculum course were available: seashore ecology; seashore ecology with geology; animal and plant ecology. Adventure courses included climbing, abseiling, canoeing or hill walking. On combined courses, students most commonly climbed, abseiled, sea level traversed and built rafts or shelters; these activities were then linked to, or interspersed with, ecology and geology fieldwork.

This paper draws upon the official evaluation of the London Challenge residential fieldwork programme. Initially, the programme addressed the perceived needs of students aged 11-14 in London boroughs with high levels of socio-economic deprivation. Government funding was made available on a sliding scale for each secondary school (using an independentlymeasured socio-economic status rating, SES; see Fisher Family Trust, 2008). SES ratings take into account factors such as relative deprivation of residential area and the number of students receiving free school meals. After three years, the programme was opened to all state secondary schools in the 33 London boroughs. In the programme's midst, the UK government launched its 'Learning Outside the Classroom Manifesto' (DfES, 2006), which constituted the first commitment of its kind to put learning outside the classroom at the heart 


\section{Research Questions}

We explored the impacts of the programme through the following research questions:

1. What is the nature of 11-14 year old inner city school students' learning during residential fieldwork experiences?

2. When examined from different perspectives - students themselves, their teachers and their parents - how are the potential benefits of residential fieldwork perceived? What relative importance do the sample groups place on different kinds of impact?

3. What evidence is there to show that students develop an understanding of scientific and environmental concepts during a short fieldwork intervention in the immediate term?

\section{Research Design}

The study involved a mixed methods approach in which data from questionnaire surveys, interviews, samples of work, student journals and observations of field courses were used to capture evidence of impact. Approximately 33,000 11-14 year olds from 849 schools took part in the London Challenge initiative between 2004 and 2008. Our intended sample included 2706 participating students from 46 state secondary schools, involved in 77 field 
courses, their teachers $(n=70)$ and parents $(n=869)$. Courses took place at 20 field centres across the UK. Gathering data via a multi-school, multi-site approach allows us to generalise our findings in a more valid way (Schofield, 1993) than from a narrow sample. The first funding phase of the programme was targeted at state secondary schools in five of the most ethnically diverse and socio-economically deprived of the 33 London boroughs. Thirteen of the 77 courses were studied in the first phase, (428 students from 13 school groups), during which research instruments were piloted. For the following two years of the programme, we continued to focus on schools with student populations of predominantly lower socioeconomic status (SES). During the final two years, courses were opened up to all state secondary schools across London; therefore schools with students across a range of SES were then included in the research. Secondary schools in the UK are independently designated SES values from 1 to 27, with 27 representing the greatest deprivation (FFT, 2008). Thirty five sample schools had cohorts with a SES of over 16 (relatively high levels of deprivation). Teachers described many participant students as having social and emotional needs.

We evaluated 13 science, 10 'other' curriculum (for example, geography or literacy), 27 adventure and 27 combined curriculum-adventure courses. Schools were assigned numbers 146 in chronological order of taking part. Many schools followed more than one course over the five-year period.

\section{Research Methods}

Data collection methods used to gather evidence exploring expectations for, and benefits of, the courses were: 
- pre- and post-course student questionnaires containing a range of attitudinal and cognitive questions;

- post-course small group student interviews at school, between two to eight weeks afterwards (governed by teacher and student availability);

- pre- and post-course teacher interviews (face-to-face or by telephone);

- $\quad$ pre- and post-course parent questionnaires (phases 2-6);

- observational visits to17 courses by one of us.

\section{Student and Parental Questionnaires: Design, Challenge and Administration}

Student questionnaires were typically 28 -item instruments, posing a mix of closed and open questions. Students were asked to identify their questionnaires by name in order to facilitate matching of pre- and post-instruments. Each student was then assigned an anonymous alphanumeric code identifier. Whilst lack of anonymity may have influenced responses, we were unable to assign code identifiers reliably via administering teachers. Teachers were asked to reassure respondents of the confidentiality of their completed surveys. The first 14 questions used a 4-point Likert-type scale to gauge attitudes toward science, geography, physical education and so forth as well as social, affective and physical issues pertinent to outdoor learning, as defined by the Rickinson et al. (2004) framework. In common with other studies, a number of methodological problems arose associated with the pre-and post-test design. Many students did not respond to all 14 items, some gave more than one response, whilst others gave identical responses to all items. It is probable that there was a degree of pre-test contamination (Mason and Kahle, 1988); some teachers reported that during post-test administration, students complained that they had 'already answered the questions'. We do not draw on these data in this paper. 
The questionnaire items were then more open in nature, requiring free text responses. Respondents were given no prompts. Items 15 to 19 asked students about their expectations for, their enjoyment and 'best memories' of courses. Items 20 to 22 addressed cognitive gains and understanding. These items were varied according to course type and content. A further six items (closed and open) then explored the other learning domains. The student survey instrument was trialled during the pilot first year (428 students). Limited physical space on questionnaires (two sides of A4 to assist with ease of administration) was likely to lead to restricted range and depth of written responses. Experienced science teachers and FSC tutors judged the content validity of the cognitive questions. Cognitive questions were designed to explore broad ideas related to course activities, but depth and specificity of questions was limited by the need to gather data from a wide range of courses. In addition, the evolving nature of the London Challenge programme over five years led to continual modification of research instruments. In the pilot year, students were simply asked to describe new science ideas or skills learnt during field courses. Their responses subsequently framed more specific questions where possible. All instruments are available from the first author; a small number of example items are provided below.

Pre-course student questionnaires were sent to lead teachers approximately one month prior to field courses. Neither of us was present during the completion of questionnaires but teachers were asked to ensure individual completion, in confidence, and to give sufficient time to the task. Post-course questionnaires were to be completed four to six weeks afterwards. 


\section{Student and Teacher Interviews}

Teacher and student interviews were semi-structured. Teachers were asked for their expectations (pre-course) and perceived impacts (post-course) for students, before more specific questions pertaining to cognitive, affective, social and physical impacts were addressed. To explore the opening question on the second side of the student survey in which respondents were asked to record their two 'best' memories, students were prompted to offer examples of expectation and outcome other than those they considered to be personally most significant.

\section{Observational visits}

One of us made extensive field notes, sampled students' work and journals, took photographs and made a small number of video / audio recordings during visits to 17 courses; these were seven science, two 'other' curriculum, three adventure and five combined curriculumadventure. 


\section{Data Analysis}

We adopted the key Rickinson et al. (2004) definitions within the four domains to initiate our data analysis framework (p16):

- cognitive; concerning knowledge gain, understanding and inquiry skills

- affective; encompassing personal attitudes, values, beliefs and self-perceptions

- $\quad$ social; including communication skills, leadership, friendship and teamwork

- $\quad$ physical / behavioural; relating to physical fitness, motor skills, personal behaviours and actions.

A more fine-grained analysis in which codings emerged from the data was then developed to categorise our findings. Data from surveys, transcripts of interviews, video / audio recordings and observational field notes were examined. Fifty two different fine-grained categories of impact were defined, as shown in Table 1.

Insert Table 1

Results are reported from the perspectives of students, their teachers and their parents. The full range of categories varied minimally between sample groups. To illustrate analytical coding, student data such as 'the caves were made of limestone' led to the generation of the category 'cognitive impact>knowledge gain $>$ learn about science'. In addition, this evidence demonstrates 'real-world understanding', in the same domain, and there is certainly overlap between a number of fine-grained categories. All data were subjected to the same process of analytical categorisation. 


\section{Results}

Typically schools took 25-30 students on a field course; priority was given to students receiving free school meals in the first three years of the programme. Teachers adopted strategies for defining student entitlement to participate such as recognition for hard work, a boost for achievement, encouragement of choice of subject post-14 (for example, geography) or development of team spirit. Most teachers briefed students beforehand simply by describing intended course activities. Four groups were given very detailed pre-course information and three groups received no prior information. Teachers did not tend to focus on subject-specific content prior to field courses as all but one group of students were from a diverse range of in-school teaching groups; four included students of mixed-age.

$1685(62 \%)$ pre-course and $1177(43 \%)$ post-course student surveys were returned from the 77 groups in the study. Attrition rates were high post-course because busy teachers, and students with other priorities, were not always willing or able to support the survey. 608 (70\%) pre- and $261(30 \%)$ post-course surveys were received from parents in the 55 groups to whom they were sent. All student interviews were conducted in schools ( $n=170$, from 35 courses) with high levels of social deprivation; in the first three years of the programme participant students were in receipt of free school meals. Thereafter, participant selection was at the discretion of teachers.

The Nature of Learning Experiences during Residential Fieldwork 
London Challenge was the first residential experience for $32 \%$ of responding students, making their impressions of its quality potentially influential in future participation. Students expressed excitement and held high hopes at the prospect, as illustrated by one girl thus:

One night at home, I thought to myself: look at all the things I ain't done in my life, I'm just wasting it sitting in the blocks in the south (London). Then this trip came along ... (so) I went to my Dad's house and got $£ 30$ out of his savings bucket (student, school 35).

Teachers and parents were overwhelming supportive of the field courses, stressing the value of the authentic residential context for students from deprived areas:

The opportunity to take difficult students from challenging backgrounds away on a fieldwork residential course is invaluable; it has the potential to change things (teacher, school 1).

It's fantastic that London kids get to experience a rural environment (parent, school 2).

We were going in and out of caves, looking down the cliffs - things you can't teach, so now it's just there for them to draw on naturally. And actually, for the group who went last year, we are seeing an increase in the numbers wanting to study Advanced level (16-18) geography (teacher, school 24). 
Several lead teachers and senior managers in schools recognised the value of the residential nature of courses and instigated new school initiatives as a result:

\begin{abstract}
Our Deputy Head has booked the centre for a series of weekend examination revision residentials for Year 11 (16 year olds) - he can see the immediate difference the course has made to the kids' attitudes towards learning (teacher, school 1).
\end{abstract}

After organising the trip, we applied for and have just been awarded, a grant from ( $a$ well-known banking company) to continue residential experiences for our Year 7's (11 year olds) over a five year period. That's fantastic (teacher, school 2).

We've set up residential fieldwork at the NT Stackpole centre (in Wales) for the first time for our Year 12 (17 year olds; teacher, school 12).

$83 \%$ of responding students reported enjoying their fieldwork experiences. Whilst some did experience uncomfortable weather conditions on occasion (personal observation), only $2 \%$ directly described the overall experience in negative terms. Positive attitudes towards the programme were essential if further impacts were to be meaningful.

\title{
Overall Impacts of the Residentials
}

\author{
Analysis of data from surveys, interviews and field notes confirmed that all three sample \\ groups (students, teachers and parents) were most highly focused on expectations for, and \\ impacts in, the affective and social / interpersonal domains. Historically, this has been a \\ common finding even for out-of-classroom day courses (Eshach, 2007; Stocklmayer, Rennie
}


and Gilbert, 2008). The small number of research studies reporting specific benefits associated with residential curriculum fieldwork, all situated in geographical contexts (for example, Nundy, 1999) suggest that a residential setting affords students and teachers the opportunity to establish productive living and learning environments. We observed similar outcomes during curriculum courses; the establishment of 'working' trust between students who would not normally spend prolonged time with one another in school (where social tensions ran high):

At the start of the week, some people weren't listening; they were taking over and doing their own thing. But then, we realised the first thing you need to do is choose a leader and everyone needs to take turns (students, school 25).

Three to five day courses immersed students in the development of practical inquiry skills, over several days, allowing the revisiting of ideas and challenges, and occasionally rerunning investigations:

The first time we tried a beach transect, the students just couldn't understand what they were trying to achieve. So we went back the next day and they were much more successful (teacher, school 5).

In school, due to pressures of time and the quest for correct outcomes, if experiments 'fail' teachers may often present 'model' results to students rather than re-staging tasks (Claxton, 1986). Moreover, collaborative developments were particularly strong in combined curriculum-adventure and adventure courses. Planned collaborative activities prior to curriculum tasks paved the way for effective teamwork: 


\begin{abstract}
Activities such as climbing and abseiling, during which students readily recognised the implicit need for trust and teamwork, also fostered cooperative approaches to subsequent curriculum tasks. Positive physical impacts resulted from challenging activities such as climbing and hiking, and teachers cited evidence for behavioural impacts more frequently than the other two sample groups.
\end{abstract}

Emergent expectations and impacts in the four Rickinson et al. developmental domains are shown in Table 2, in rank order of importance, from the perspectives of students, teachers and parents respectively. The findings are generated from pre- and post-questionnaire data for students and parents by frequency analysis using the statistical software programme SPSS, and from pre- and post-interviews for students and teachers by coding transcripts. Data were assigned multiple codings where applicable to reflect overlap between fine-grained categories. For example, a student in school 20 stated during an interview he had learnt that pebbles can move along a beach due to long shore drift and this new knowledge had helped him to attain his best ever mark in a science test when back at school. The three categories within 'cognitive gains> understanding ideas' in Table 2 were therefore applicable. 


\title{
Insert Table 2
}

The 52 fine-grained categories (originally outlined in Table 1) were conflated to the original broad categories, which we then expand upon with more nuanced findings below. Overall, analyses shown in Table 2 indicate that all sample groups were in broad agreement; that is to say, developing teamwork skills and building relationships were the most important perceived gains made during the programme. Indeed, the spontaneous focus on the importance of social / interpersonal and affective expectations and perceived impacts seemed to overshadow cognitive developments for the sample groups. This was particularly so in the eyes of the students, who rarely mentioned the notion of 'learning ideas or skills' in interviews when asked about their 'strongest memories'. In the early phases of the programme, several teachers explicitly 'played down' the curriculum aspects of courses, seeing their overt mention as a potential barrier to student participation and potential engagement. Teachers sometimes had difficulty filling places on curriculum-only courses:

\footnotetext{
I was really surprised; I had intended to take all the recycling representatives but several didn't want to go - mind you, when the kids came back and were talking about how great it had been, the others wished they'd gone (teacher, school 27).
}

\begin{abstract}
Notably, on combined courses students worked on curriculum activities enthusiastically, in contrast to the occasional reluctance observed on curriculum-only courses.
\end{abstract}

We now explore the main impacts in greater depth in each developmental domain. We begin by outlining the key social and affective gains, including those related to the residential 
context of the field courses. Survey data are expanded upon and illustrated further by data from interviews throughout.

\section{Social Impacts: Students, Teachers and Parents}

There was an increase in the number of student friendships, the most frequently cited benefit of the residential courses from the students' perspectives. $85 \%$ hoped to develop new friendships beforehand and $87 \%$ of respondents reported actually doing so $(n=950)$. Students welcomed the prospect of being away with friends. This was confirmed in interviews:

Friendships grew and students are now interacting back at school; the trip initiated this (teacher, school 2).

This teacher was a Pastoral Head for 170 12-13 year olds. She hoped that the residential experience would help to counteract all-too-familiar patterns of social division amongst her students. Such counteraction did occur, as shown by her example and in others:

Because we put them in non-friendship groups, they made new friends and now at school I see them saying hello in the corridors. The value of that is immense (teacher, school 18).

We were put on a table with three girls, can't even say I remember seeing them at school. We all became friends.

Yeah, you really see people in a different way than in school (interview conversation, students, school 41). 
Teachers agreed with students, noting improved levels of trust as well as more relaxed interactions than at school. Farnham and Mutrie (1997) reported similar findings for students with special educational needs. Teachers and students related with a greater degree of informality than is often afforded in school, as they lived and worked alongside one another for several days:

At school, we didn't like Ms P, she was strict, but on the trip we got to know her. I think 'cos we are naughty, that's why she was that way.

She's nicer now we're back; she comes into our room and says 'hi' (interview conversation, students, school 5).

We learnt more about the children in four days than we would in six months at school (teacher, school 12).

These outcomes reinforce the perceived value of the residential nature of the courses.

Teachers truly become in loco parentis during residential work. Teachers' encouragement for students, enhanced by active involvement, had a notable effect on motivation:

\author{
Some of us showed our fear during climbing; the students were surprised but then \\ realised it's OK to show emotions (teacher, school 16).
}

\begin{abstract}
Parents ( $n=243$ ) cited positive social interactions most frequently as an important expectation for their children:
\end{abstract}


I want my son to live well with his peers while he's away (parent, school 4).

\begin{abstract}
It is difficult to adequately convey the high value placed upon effective social interaction by students, teachers and parents in the London Challenge programme. Such positive interactions are not a foregone conclusion in the everyday lives of students in deprived areas of London often affected by considerable social tension.
\end{abstract}

\begin{abstract}
We now turn to the second most frequently cited benefit of the programme: improved teamwork. Improving teamwork had not been an apparent priority for students beforehand, but was in fact their third most frequently stated gain: $85 \%$ of responding students $(n=1177)$ reported they had developed positive teamwork skills, citing 'co-operation, listening well and good discussion' as key contributors to effective collaboration.
\end{abstract}
Teachers $(n=75)$ and parents $(n=240)$ were in agreement about the value of developing teamwork:

Students negotiated whereas they wouldn't in school (teacher, school 7).

\begin{abstract}
Abseiling and rafting were particularly effective in promoting teamwork; students actively encouraged one another to overcome challenges and to celebrate success. Leaders emerged, sometimes unexpectedly:
\end{abstract}

You see people coming out as leaders and you wouldn't necessarily expect them to.

It's interesting too how children recognise who is having good ideas (teacher, school $37)$. 
Students valued the team-building activities, stating that often people became involved in activities more willingly than in school, recognising the need for reliance on peers. The focus on positive student relationships was overt during field courses. Some of the affective impacts, however, were played out in a more subtle fashion.

\section{Affective Impacts: Students, Teachers and Parents}

The London Challenge programme took inner city students out of their comfort zones into rural areas of the UK, thereby creating opportunities for personal development in a number of ways. During adventure courses, students were seen striving to achieve their best and their self-perceptions improved as a consequence:

I took on hard challenges; rock climbing was scary and I felt like coming down but I knew I would regret it if I did so I carried on. I'm so proud of myself (student, school $35)$.

In combined curriculum-adventure courses, students displayed high levels of motivation showing that the authentic environment contributed to conceptual engagement. Novel practical activities engaged students:

The coastal experiences really helped to engage them with Year 8 geology; now they've seen a stack (teacher, school 12).

Parents saw changes in their children's attitudes toward learning: 
D had a very positive experience; it's changed his opinion about school - that you $\underline{\text { can }}$ have fun whilst learning (parent, school 4).

Once again, none of these attributes came easily for the students in question; parents in particular were keen for students to develop key life skills:

I want my daughter to gain a sense of independence, self discovery and responsibility (parent, school 31).

Moreover, the residential setting directly enabled many students' to develop simple but essential life skills:

\begin{abstract}
One boy really surprised me. He has a statement of special needs, was very shy and had low self-esteem. I had to push him to come but he was very good. He showed the others skills they didn't realise he had - playing football, winning cards in the evenings. He gained respect (teacher, school 3).
\end{abstract}

\begin{abstract}
A couple of kids were real loners; one was new in school and hadn't made any friends but he was the star. He came out of himself and we now see it in school - he's making eye contact and talking with his peers. His school work has come on leaps and bounds (teacher, school 12).
\end{abstract}

Measuring students' attitudes toward environmental issues has long been of interest (Armstrong and Impara, 1991), although measuring attitudinal change has often been 
inconclusive. The majority of field centres in the London Challenge programme are run to promote ecological sustainability so students actively participated in recycling materials and so forth. As a result, they demonstrated changed behaviours and attitudes upon returning home:

Now if I go upstairs I make sure I turn the light off again; if I hear my brother's telly, I'll turn it off. And I'll check taps are off.

(In school) I think it's quite wasteful, like in French, it was a sunny day, we had the curtains open but we still had the lights on (interview conversation, students, school 27).

On courses with specific foci on environmental issues, students gave a broader range of responses to the following survey item post-course: 'Give an example of an environmental problem happening at the moment'. Beforehand, $48 \%$ of respondents ( $\mathrm{n}=150$ from 7 schools) suggested 'global warming' and 29\% 'pollution'. Afterwards, 30\% stated 'global warming' but now $14 \%$ 'littering', 4\% 'deforestation' and 2\% 'energy waste' (n=146) were also mentioned. It is likely that the latter three issues were directly related to course inputs. Their experiences at field centres therefore had some immediate influence on personal behaviours, but as Rickinson et al. (2004) suggest, environmental awareness was not automatically elevated by being out in nature.

Physical Impacts: Students, Teachers and Parents

Physical / behavioural developments were witnessed by teachers. Benefits ensued from several activities designed to develop affective attributes: 
One boy, A, can be quite disruptive; he had fished before so rather than try to get out of things as he does in school, he was often totally absorbed. And then at the other end, we had two or three boys who are able mathematicians; they were just flying with some of the graphical work - by the end of the week they were doing GCSE level work (15-16 year-old equivalent); amazing really - that would not be possible at school (teacher, school 5).

We took four difficult boys specifically and now they are better in lessons at school (teacher, school 19).

Fox and Avramidis (2003) report improvements in behavioural engagement of this nature for students with emotional and behavioural difficulties learning outdoors.

Of the three sample groups, parents voluntarily focused most readily upon cognitive development. Exploring evidence for such gains is pertinent because whilst there is greater evidence for social and affective development during field courses, particularly when residential (Rickinson et al., 2004; Braund and Reiss, 2006), senior managers in schools seem to find sanctioning such events difficult unless there is a clear case for curriculum-related learning.

\section{Cognitive Impacts: Students, Teachers and Parents}

Gaining quantitative evidence for specific cognitive gains during the London Challenge programme was extremely challenging. Providers offered schools generic field courses, but 
the content of each course varied; as independent evaluators we often only established the general nature of course activities beforehand. For example, at one centre, seashore ecology included freshwater pond dipping, a beach transect, rock pool ecology (Figure 1) and spending time in the laboratory analysing results from investigations. Students collected plankton during a speedboat ride. At another centres, seashore ecology with geology was more focused on examining coastal erosion and sea defences.

\section{Insert Figure 1}

The diverse range of courses, in non-experimental, naturalistic settings, subjected us to considerable limitations in terms of item specificity. We therefore designed a small number of items (typically three or four) for different types of course. We aimed to broadly measure students' understanding of scientific ideas in the rural contexts in which they worked. Question items were refined after the pilot phase. For example, the term 'habitat' was rarely used by students in the pilot study when they gave examples of 'seeing animals / plants' in response to an item exploring new ideas / skills learnt. Therefore a survey item was introduced to explore whether students did understand the relevance of 'habitat'. Student responses were compared pre- and post-course to gauge progress in using scientific terms accurately, or assimilation of new ideas, using chi-squared associations $\left(\chi^{2}\right)$. The following six items were given to more than one school group:

1. What do we call the general place in nature where animals or plants live? Compare frequency of response 'habitat' pre- and post-course $\left(\chi^{2}=3.67, \mathrm{df}=1, \mathrm{p}=0.06\right)$.

2. Where exactly will you find living things on a rocky shore? Compare reference to under/on a rock/in a rock pool $\left(\chi^{2}=6.11, \mathrm{df}=1, \mathrm{p}=0.01\right)$. 
3. Which animals might you find living on a rocky shore? Compare frequency of accurate responses $\left(\chi^{2}=0.13, \mathrm{df}=1, \mathrm{p}=0.72, \mathrm{~ns}\right)$

4. What is an invertebrate? Compare frequency of response 'has a backbone' $\left(\chi^{2}=0.08\right.$, $\mathrm{df}=1, \mathrm{p}=0.61, \mathrm{~ns})$

5. What might happen to pebbles on a beach? Compare frequency of accurate responses $\left(\chi^{2}=0.20, \mathrm{df}=1, \mathrm{p}=0.65, \mathrm{~ns}\right)$

6. Name, if you can, three plants / animals that live in a woodland / forest / field in the UK. Compare frequency of non-farm animals / pets cited $\left(\chi^{2}=28.26, \mathrm{df}=1, \mathrm{p}=\right.$ 0.0001).

The only items that indicate a strong association were items 2 and 6. Item 1 shows a tendency for an association, although this is not quite significant at the $\mathrm{p}<0.05$ (2-tailed) level. We suggest this raises some methodological issues around the use of questionnaire surveys to elicit students' ideas in these kinds of non-formal 'distance' contexts because post-course student interviews uncovered more robust evidence showing a high proportion of individuals had learnt new ideas.

When questioned back at school (up to eight weeks post-course), all students in our 35 sample groups $(n=170)$ were able to outline knowledge gains or describe skills they developed. Interviews were conducted in a semi-structured manner, with emphasis on students offering personal examples. Interviewees were initially asked for their strongest recollections, to verify the survey data. These were often associated with a 'memorable moment': a fellow student falling in the water and so on. To illustrate, recollections made by one group (school 46) are given in Table 3, indicating students' own justifications for the particular memory. 


\title{
Insert Table 3
}

\begin{abstract}
Students in school 46 had been expecting seashore ecology with geology, and were very positive about the inclusion of adventure activities. Curriculum tasks included beach ecology and exploration of coastal erosion. Afterwards, students did not actively volunteer evidence of cognitive gains (in response to the question below) without prompting; this was typical of student interviewees. Moreover, only two out of 35 parents (school 46) reported offspring recounting 'learning ideas' at home afterwards. Nevertheless, when invited to do so, students gave accurate examples of scientific ideas explored during fieldwork. Individuals were asked the following question:
\end{abstract}

Can you tell me something new, something different that you didn't know, or can you do something that you couldn't do, as a result of going on your field course?

Our purpose was to elicit non-directed, free responses prior to asking more specific, sciencerelated questions. Some illustrative data were:

We saw about 20 different things, like little fish and water fleas (student, school 13).

\begin{abstract}
We found crabs, and shrimps, and a funny, purple jellyfish thing which kept stinging the crab. I've never done anything like that before (student, school 15).
\end{abstract}

I think I like science more now since the trip ... because I know more about animals and plants. 
Yeah, because we're doing habitats now in science, and we saw a hawk and their habitat is a cave (interview conversation, students, school 25).

We went to a wind farm (Figure 2); people say that they're noisy but actually it was just a swishing noise; they can run for 20 years once built (student, school 27).

I saw 'Dracula's fangs' in a cave; it was an example of a stalactite - calcium sulfate comes out of the water as it drips down and 'sticks' to other particles (student, school 46).

Insert Figure 2

These responses demonstrate learning beyond examples accessed through questionnaire items:
I'm astonished that no one mentioned being on the rocky shore ... I was amazed at its impact. The students were all there, bottoms in the air, discovering starfish and all sorts. Every single kid was totally focused on what they were doing, so different from being in the classroom (teacher, school 46).

\begin{abstract}
Some teachers were definite about the value of the fieldwork opportunities in terms of inherent contribution to students' longer-term learning back at school:
\end{abstract}

Students learnt a lot about scientific investigation, and asked lots of questions. In curriculum terms, they learnt about feeding relationships, identifying animals and 
their adaptations, habitats. I heard one kid talking in the corridor (at school) saying 'we held crabs and saw them moving' so they've been telling their friends about what they learnt (teacher, school 5).

I can't really hope that they will automatically be able to tell you the ideas in science they learnt, but I know when it's reintroduced later on, they will be much quicker at picking it up. They had a working model for erosion and the rock cycle so it's there for them (teacher, school 32).

Individuals communicated ideas accurately in presentation-to-peers sessions which often concluded fieldwork activities (personal observation). Naturally, certain groups established purposeful learning communities more rapidly than others. Students tended to spend more 'formal' time in the classroom before and after curriculum activities (Figure 3). Occasionally, students described this as 'too much like school' (student, school 24) and were less engaged than when outside.

Insert Figure 3

\section{Discussion and Implications}

The nature of out-of-classroom learning in a residential fieldwork context for inner city students from London, UK, is complex. Our study provides empirical evidence that fieldwork can potentially help to address socially deprived students' needs in terms of developing teamwork and socialisation, and in 'doing' science. The four developmental domain framework defined by Rickinson et al. (2004) provided us with a valuable analytical tool for 
interpreting the kinds of impacts afforded by the London Challenge programme. Our findings reveal more evident learning in social, affective and behavioural domains than in cognitive dimensions, in common with other recent research (The American Camp Association, 2005; Eshach, 2007). Such a situation may stem, in part, from participant expectations; all groups of students, teachers and parents stressed the perceived value of social and affective gains. Nevertheless, two additional findings in our study are of note. First, students did make cognitive gains and these were revealed to a greater extent by interviews than by written questionnaires. This finding concurs with a number of empirical studies looking primarily at cognitive gains, although several have compared learning during fieldwork with other classroom-based teaching approaches (Mackenzie and White, 1982; Hofstein and Rosenfeld, 1996; Nundy, 2001; Eke-Hamilton, 2007). Such studies go some way to illuminating positive cognitive gains when undertaking fieldwork; however, direct comparisons of learning for differing student samples are problematic. Also, earlier studies have often failed to uncover convincing evidence that there is a link between outdoor experience and environmental understanding (Rickinson et al., 2004). We found courses did have consequences for students' environmental behaviours, sometimes translating into them critiquing their schools (for example, 'wasting' energy) or changing their own behaviour ('saving' energy). The realworld learning contexts of the London Challenge programme could certainly not be replicated directly in schools; therefore we suggest that students benefitted from opportunities to take part in science inquiry in authentic settings, and were positive about links to learning in school.

Our second additional finding shows that rather than seeing learning in the four domains identified by Rickinson et al. (2004) as alternatives, or even in competition, learning opportunities complemented one another across the domains. Nundy (1999) asserts that 
affective and social benefits accrue as a result of residential fieldwork, which he goes on to suggest supported cognitive gains which were not seen in control groups in a primary school. Whilst our study did not aim to directly compare cognitive gains in and outside the classroom (clearly, with ever-advancing in-classroom technology, it is possible for students to successfully learn about scientific ideas through a variety of approaches), the real-world opportunities for 'doing' science were perceived as being valuable by participants, their teachers and their parents.

We attempted to probe students' 'free choice' learning through the survey instruments; however, this was problematic. In fact, student interview data illustrated cognitive impacts more convincingly. This might suggest that in the context of 'non-formal' learning students were unwilling to fully engage with survey items. We suggest that oral representation of understanding of ideas and developed practical skills more easily allowed students to express their own situated learning outcomes. Eshach (2007) notes that researchers have rarely asked students for personal impressions of the nature and value of fieldwork; our study hopefully makes a pertinent contribution, though it is likely that the questionnaires we employed were typically seen as unwanted intrusions more fitting of a 'formal' school experience. In future studies, we recommend that researchers pay attention to such issues.

It is perhaps unsurprising that residential fieldwork participants tend to recall and value social and affective outcomes during out-of-classroom experiences. Students expressed high expectations for potential 'free choice' learning (Falk and Storksdieck, 2010) which they hoped courses would afford them. Several teachers were convinced of the value of such fieldwork contexts in providing links to future in-school learning, akin to Brody and Tomkiewicz's (2002) notion of cognitive bridges. We also suggest our findings demonstrate 
The distinctive context of the London Challenge programme demonstrates advantages in schools drawing upon expertise from the informal sector (Stocklmayer et al., 2010). Most schools in our study were complex, multicultural comprehensives in deprived areas of London in which students and their families face daily social and personal challenges. Lead teachers confirmed that students often had little opportunity for collaborative work in school science lessons. Simply working in collegial ways provided novel opportunity to work in 'real teams of scientists'. Moreover, during recent decades, time for informal socialisation (for example, lunchtimes) in London schools has commonly been reduced in an attempt to minimise anti-social behaviour. Working closely and spending time together during residential field courses put students in atypical situations, from which they benefited. Many of the students in our study are likely to remain members of the lowest socio-economic group of learners, failing to achieve their academic potential in the UK by age 18 ; the UK has a higher than average socio-economic education gap (Feinstein, 2003). We suggest the London Challenge programme added much-needed variety, stimulus and reality to educational experience and well-being for students from socially deprived areas.

The impacts of residential fieldwork can be interpreted in a number of ways. We recognise that our sample students will have been influenced by the novelty of being away from home, learning in a less formal way than in school, which may stimulate strong memories. However, Nundy (1999) states that 'key memory episodes' associated with fieldwork can 
enhance cognitive gains for students, corroborating similar findings by Mackenzie and White (1982). To try to explain such memorable feelings, Falk and Dierking draw on the thoughts of psychologist Csikszantmihalyi (2000, p24). Csikszantmihalyi proposes that people who pursue intense activities (such as rock climbing) thrive on a kind of 'flow experience'; the total immersion in a high-demand situation gives immediacy of feedback which in itself sustains motivation and drive. Perhaps adventure and combined field courses in particular gave students a 'flow experience' of a kind, more so than could readily be achieved in school. Continued focus on the importance of emotional well-being and its effects on conceptual learning (Department for Children, Families and Schools, DCSF, 2008) might also imply that far from reducing the frequency of residential fieldwork, governments and schools would do well to place increased emphasis on its potential for enhancing social and affective skills. In the current economic situation in developed countries, this is perhaps a challenging financial proposition, so ways in which the formal school and informal sectors can work together need to be explored (Stocklmayer et al., 2010).

Moreover, meaningful learning is essentially long-term, with many peaks, troughs, spirals and unexpected pathways. Setting the agenda for the design and implementation of effective fieldwork needs to be tackled from this starting point. Students on curriculum-only field courses were often less enthusiastic about their experiences than their counterparts on combined curriculum-adventure courses. Ecologists enthuse about young people interacting with organisms, often holding their heads in disbelief when a student is unable to identify even a simple buttercup in the field. However, as one speaker at a 2009 UK parliamentary briefing commented, inner city students may not have a natural inclination towards such fieldwork (personal observation). Adult educators perhaps make unjustified assumptions about what students should experience during fieldwork, thereby reducing potential 'free 
The majority of teachers who took part in the London Challenge programme were inspired by fieldwork activities and gained confidence in organising and leading residential courses. Several led more than one course within the programme, and others began to see the benefits of, and to plan, residential fieldwork for students in their schools where none had gone before. We suggest that science teachers and field course providers need to take account of the potential successes of fieldwork that incorporates physical adventure alongside curriculum activities. Enhancing students' enjoyment of science during fieldwork experiences through linked 'adventure' seemed to open up greater possibility of cognitive engagement. The value of social and affective impacts needs to be fully recognised in terms of the underpinning of learning in out-of-classroom contexts. Encouragingly, the FSC has more recently designed combined adventure-curriculum courses for schools in other parts of the UK, incorporating literacy and numeracy as well as science, and early signs (personal communication) are that students and teachers are very positive about such approaches.

\section{References}

Aikenhead, G. (2006). Science Education for Everyday Life. New York: Teachers College Press. 
Armstrong, J. and Impara, J. (1991). The impact of an environmental education program on knowledge and attitude. Journal of Environmental Education, 22(4), 36-40.

Bebbington, A. (2004). Learning at residential field centres. In Braund, M. and Reiss, M. (2004). Learning Science Outside the Classroom. (pp 47-62) London, UK:

RoutledgeFalmer.

Braund, M. and Reiss, M. (2006). Towards a more authentic science curriculum: the contribution of out-of-school learning. International Journal of Science Education, 28(12), 1373-1388.

Brody, M. and Tomkiewicz, W. (2002). Park visitors' understandings, values and beliefs related to their experience at Midway Geyser Basin, Yellowstone National Park, USA. International Journal of Science Education, 24(11), 1119-1141.

Brookes, A. (2002). Lost in the Australian bush: outdoor education as curriculum. Journal of Curriculum Studies, 34(4), 405-425.

Cerini, B., Murray, I. and Reiss, M. (2003). Student Review of the Science Curriculum: Major findings. London, UK: Planet Science.

Chowdry, H., Crawford, C. and Goodman, A. (2009). Drivers and Barriers to Educational Success - Evidence from the Longitudinal Study of Young People in England. London, UK: DCSF Research Report 102.

Claxton, G. (1986). The alternative conceiver's conceptions. Studies in Science Education, $13,123-130$.

Department for Education and Skills $(1988,1995)$. National Curriculum for Science in England. http://www.standards.dfes.gov.uk.

Department for Education and Skills, Working Group on 14-19 Reform (2004). 14-19 Curriculum and Qualifications Reform: Interim Report of the Working Group on 14-19 Reform. London, UK. 
Department for Education and Skills (2005). Social and emotional aspects of learning. http://nationalstrategies.standards.dcsf.gov.uk.

Department for Children, Schools and Families (2006). The Learning Outside the Classroom Manifesto. http://www.dcsf.gov.uk/pns/DisplayPN.cgi?pn_id=2006_0175.

Department for Children, Schools and Families (2008). The National Curriculum for Science. http://curriculum.qcda.gov.uk/key-stages-3-and-4/subjects/key-stage3/science/index.aspx.

Eke-Hamilton, J. (2007). Relative effectiveness of expository and field trip methods of teaching on students' achievement in ecology. International Journal of Science Education, 29(15), 1869-1889.

Eshach, H. (2007). Bridging in-school and out-of-school learning: formal, non-formal and informal learning. Journal of Science Education and Technology, 16(2), 171-190.

Falk, J. and Dierking, L. (2000) Learning From Museums. Walnut Creek, USA: Alta Mira Press, Rowman and Littlefield.

Falk, J. and Storksdieck, M. (2010) Science learning in a leisure setting. Journal of Research in Science Teaching, 47(2), 194-212.

Farnham, M. and Mutrie, N. (1997). The potential benefits of outdoor development for children with special needs. British Journal of Special Education, 24(1), 31-38.

Feinstein, L. (2003). Inequality in the early cognitive development of British children in the 1970 Cohort. Economica, 70(277), 73-97. Policy summary available at http://cep.lse.ac.uk/pubs/download/CP146.pdf.

Fisher Family Trust (2008). http://www.fischertrust.org.

Fox, P. and Avramidis, E. (2003). An evaluation of an outdoor education programme for students with emotional and behavourial difficulties. Emotional and Behavioural Difficulties, 8(4), 267-282. 
Hart, P. (2002). Environment in the science curriculum: the politics of change in the PanCanadian science curriculum development process. International Journal of Science Education, 24(11), 1239-1254.

Hodson, D. (2008). Towards Scientific Literacy: A teachers' guide to the history, philosophy and sociology of science. Rotterdam: SensePublishers.

Hofstein, A. and Rosenfeld, S. (1996). Bridging the gap between formal and informal science learning. Studies in Science Education, 28, 87-112.

Kendall, S., Murfield, J., Dillon, J. and Wilkin, A. (2006). Education Outside the Classroom: Research to identify what training is offered by initial teacher training institutions. Research Report 802. London, UK: National Foundation for Educational Research / Department for Education and Skills.

Lai, K. (1999). Freedom to learn: a study of the experiences of secondary school teachers and students in a geography field trip. International Research in Geographical and Environmental Education, 8(3), 239-255.

Leeming, F., Dwyer, W., Porter, B. and Cobern, M. (1993) Outcome research in environmental education: a critical review. Journal of Environmental Education, 24(4), $8-21$.

Lock, R. and Tilling, S. (2002). Ecology fieldwork in 16 to 19 biology. School Science Review, 84(307), 79-87.

Lock, R (2010). Biological fieldwork in schools and colleges in the UK: an analysis of empirical research from 1963 to 2009. Journal of Biological Education, 44(2), 58-64.

Mackenzie, A. and White, R. (1982). Field work in geography and long-term memory structures. American Educational Research Journal, 19(4), 623-632.

Mason, C. and Kahle, J. (1988). Students' attitudes toward science and science-related careers: a programme designed to promote a stimulating gender-free learning 
environment. Journal of Research in Science Teaching, 26(1), 25-39.

Millar, R. and Osborne, J. (eds) (1998). Beyond 2000: Science Education for the Future. London: King's College London.

Nundy, S. (1999). The fieldwork effect: the role and impact of fieldwork in the upper primary school. International Research in Geographical and Environmental Education, 8(2), 190-198.

Nundy, S. (2001). Thoughts from the field: in their own words ... . Horizons, 4, 20-22.

Office for Standards in Education (Ofsted/HMI), (2004). Outdoor Education: Aspects of good practice. London, UK: HMSO.

Osborne, J. and Collins, S. (2001). Pupils' views of the role and value of the science curriculum: a focus-group study. International Journal of Science Education, 23(5), 441467.

Osborne, J. and Dillon, J. (2007). Research on learning in informal contexts: advancing the field? International Journal of Science Education, 29(12), 1441-1445.

Prokop, P., Tuncer, G. and Kvasnicak, R. (2007). Short-term effects of field programme on students' knowledge and attitude toward biology: a Slovak experience. Journal of Science Education and Technology, 16(3), 247-255.

Rickinson, M., Dillon, J., Tearney, K., Morris, M., Choi, M. Y., Sanders, D. and Benefield, P. (2004). A Review of Research on Outdoor Learning. Slough, UK: National Foundation for Educational Research.

Roth, W.-M., van Eijck, M., Reis, G. and Hsu, P-L. (2008). Authentic Science Revisited: In praise of diversity, heterogeneity, hybridity. Rotterdam: Sense.

Scharfenberg, F-J., Bogner, F. and Klutke, S. (2008). A category-based video-analysis of students' activities in an out-of-school hands-on gene technology lesson. International Journal of Science Education, 30(4), 451-467. 
Schreiner, C. (2006). Exploring a ROSE-garden: Norwegian youth's orientations towards science - seen as signs of late modern identities. Doctoral thesis, University of Oslo, Faculty of Education, Department of Teacher Education and School Development, Oslo. Available at: http://www.ils.uio.no/english/rose/network/countries/norway/eng/norschreiner-thesis.pdf.

Schofield, J. (1993). Increasing the generalizability of qualitative research. In M. Hammersley (Ed.), Educational research: Current issues (pp. 91-113). London, UK: Paul Chapman.

Stocklmayer, S., Rennie, L. and Gilbert, J. (2010). The roles of the formal and informal sectors in the provision of effective science education. Studies in Science Education, $46(1), 1-44$.

Tilling, S. (2004). Fieldwork in UK secondary schools: influences and provision. Journal of Biological Education, 38(2), 54-58.

The American Camp Association (2005). Directions: Youth Development Outcomes of the Camp Experience. http://www.acacamps.org/research/enhance/directions.php.

USA National Academy of Science (2007). Rising above the Gathering Storm: Energizing and employing America for a brighter economic future. Committee on Prospering in the Global Economy of the 21st Century: An Agenda for American Science and Technology. Washington, DC, USA: National Academies Press National Academy of Sciences, National Academy of Engineering, Institute of Medicine.

Wellington, J. and Ireson, G. (2008). Science Learning: Science Teaching. Abingdon, UK: Routledge.

Wood, D. (1998). How Children Think and Learn: The social contexts of cognitive development. Oxford, UK: Open University Press. 
Zoldosova, K. and Prokop, P. (2006). Education in the field influences children's ideas and interest toward science. Journal of Science Education and Technology, 15(3), 304-313. 
Table 1. Fine-grained data analysis categories for the four Rickinson et al. (2004) developmental domains (CASP): questionnaire and interview data

\section{Cognitive domain}

Knowledge gain

- learn about science

- learn about nature

- learn about recycling

\section{Affective domain}

\section{Personal attitudes}

- do their best

- develop independence

- improve motivation to learn

- have fun (whilst

learning)

- persevere

Understanding ideas Personal values

- understand scientific ideas

- display 'real world' understanding

- raise achievement in science back at school

Inquiry skills
- map reading/
orienteering skills
- research skills
- experimental skills
- literacy skills
- explore the real
world

\section{Social / Interpersonal domain}

\section{Communication skills}

- listen well to others

- listen well to instructions

- discuss ideas

effectively
Physical /

Behavioural domain

Physical fitness

- face challenges

- participate in a hike/expedition well

- build stamina

\section{Leadership skills}

- show initiative

opportunities

- appreciate new places

- respond to ecocentre issues

- live without electrical appliances

\author{
Personal beliefs \\ - show concern for \\ environmental \\ issues
}

\section{Self-perceptions}

- build self esteem

- build self confidence

- develop self belief

- overcome fears

\section{Team work skills \\ - participate well \\ - cooperate well \\ - share ideas \\ - be supportive/helpful}

\section{Building relationships Social actions}

- make friends/be friendly

- build teacher-student relationship

- build student-other adult relationship

- be away with friends positively

- look out for each other

- look after their

\section{Physical/motor} skills

- develop climbing skills

- learn to abseil/zip wire

- learn to canoe/raft/swim/ surf

- learn to gokart/cycle

\section{Personal behaviours}

- behave well

- look after self well

- live well with others living environment 
1

Table 2. Ranked importance of pre-course expectations for, and post-course reported gains from fieldwork experiences within the four Rickinson et al. developmental domains

$$
\text { ( } 1 \text { = highest; } 8=\text { lowest })
$$

\begin{tabular}{|c|c|c|c|c|c|c|c|}
\hline $\begin{array}{l}\text { Developmental } \\
\text { domain }\end{array}$ & $\begin{array}{l}\text { Expectation / } \\
\text { Reported gain }\end{array}$ & $\begin{array}{l}\text { Student } \\
\text { pre }\end{array}$ & $\begin{array}{c}\text { Student } \\
\text { post }\end{array}$ & $\begin{array}{l}\text { Teacher } \\
\text { pre }\end{array}$ & $\begin{array}{c}\text { Teacher } \\
\text { post }\end{array}$ & $\begin{array}{l}\text { Parent } \\
\text { pre }\end{array}$ & $\begin{array}{c}\text { Parent } \\
\text { Post }\end{array}$ \\
\hline Cognitive (C) & $\begin{array}{l}\text { Learning new } \\
\text { ideas }\end{array}$ & * & $*$ & 5 & 8 & 2 & 3 \\
\hline Affective (A) & Having fun & 4 & 4 & - & - & 6 & - \\
\hline A & $\begin{array}{l}\text { Building self } \\
\text { esteem }\end{array}$ & - & 6 & 3 & 5 & - & - \\
\hline A & $\begin{array}{l}\text { Building self } \\
\text { confidence }\end{array}$ & - & 5 & - & 4 & 4 & 5 \\
\hline A & $\begin{array}{l}\text { Developing } \\
\text { independence }\end{array}$ & - & 7 & & 6 & 5 & 4 \\
\hline A & $\begin{array}{l}\text { Improving } \\
\text { motivation to } \\
\text { learn }\end{array}$ & - & - & 4 & 7 & - & - \\
\hline A & $\begin{array}{l}\text { Seeing new } \\
\text { places }\end{array}$ & 5 & 8 & 6 & - & - & - \\
\hline $\begin{array}{l}\text { Social/ } \\
\text { Interpersonal (S) }\end{array}$ & $\begin{array}{l}\text { Improving } \\
\text { cooperation }\end{array}$ & 6 & - & 7 & 2 & - & - \\
\hline$S$ & $\begin{array}{l}\text { Improving } \\
\text { team work }\end{array}$ & - & 3 & 1 & 1 & 3 & 1 \\
\hline S & $\begin{array}{l}\text { Building } \\
\text { relationships }\end{array}$ & 1 & 1 & 2 & 3 & 1 & 2 \\
\hline S & $\begin{array}{l}\text { Being away } \\
\text { with friends }\end{array}$ & 3 & 2 & - & - & - & - \\
\hline $\begin{array}{l}\text { Physical / } \\
\text { Behavioural (P) }\end{array}$ & $\begin{array}{l}\text { Trying (a } \\
\text { variety of) new } \\
\text { activities }\end{array}$ & 2 & 1 & - & - & - & 6 \\
\hline
\end{tabular}


Table 3. Students' strongest memories from a combined curriculum-adventure course in Northern Ireland, 2008 (school 46; all nine students in small group interview included here)

\section{Student Gender Strongest memory Justification Developmental domain (some relevance to)}

We went the wrong way; was fun

Walked along way; was tiring

Saw lots of places; communicated a lot

A, S

A

A much here (London)

I was good at it; my friend tipped in

The people at the

A

$\mathrm{P}$ and hills centre were really nice

A, S, P

S

A, S

from normal, with school friends

Just had a really good A

$\mathrm{F}=$ female, $\mathrm{M}=$ male 
Figure 1. Students in school 5 carrying out a beach transect on the rocky shore 
Figure 2. Students in school 27 examining sound levels next to a wind turbine 


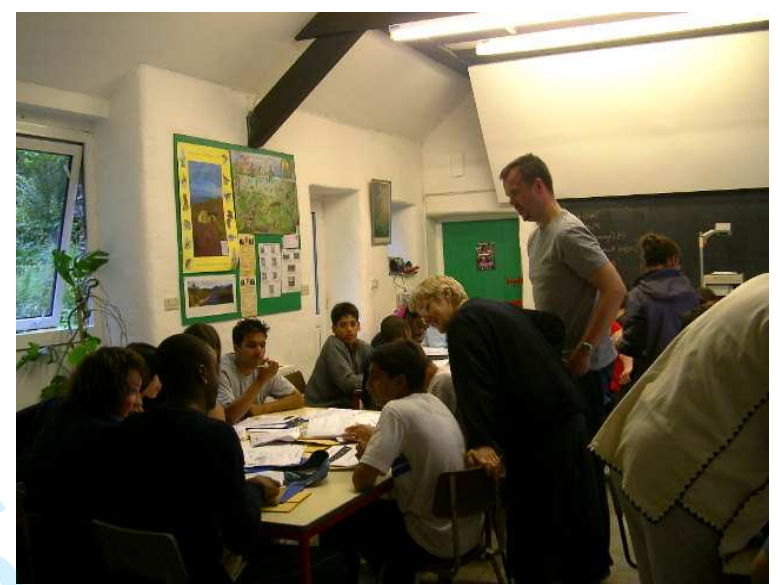

Figure 3. Students in school 24 reviewing data collected in the field 